\title{
hChAT: A Tool for the Chemoenzymatic Generation of Potential Acetyl/ Butyrylcholinesterase Inhibitors
}

\author{
Keith D. Green, ${ }^{[a]}$ Micha Fridman, ${ }^{[b]}$ and Sylvie Garneau-Tsodikova ${ }^{*[a]}$
}

Nervous system disorders, such as Alzheimer's disease $(A D)^{[1]}$ and schizophrenia, ${ }^{[2]}$ are believed to be caused in part by the loss of choline acetyltransferase (ChAT) expression and activity, which is responsible for the formation of the neurotransmitter acetylcholine (ACh). ACh is biosynthesized by ChAT by acetylation of choline, which is in turn biosynthesized from L-serine. ${ }^{[3]}$ $\mathrm{ACh}$ is involved in many neurological signaling pathways in the parasympathetic, sympathetic,<smiles>COc1cc2c(cc1OC)C(=O)C(CC1CCN(Cc3ccccc3)CC1)C2</smiles><smiles>CCN(C)C(=O)Oc1cccc([C@@H](C)N(C)C)c1</smiles>

Rivastigmine (Exelon ${ }^{\circledR}$ )

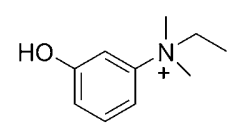

Edrophonium<smiles></smiles>

Neostigmine

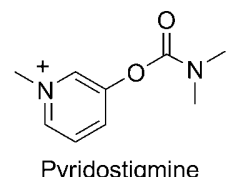

Pyridostigmine
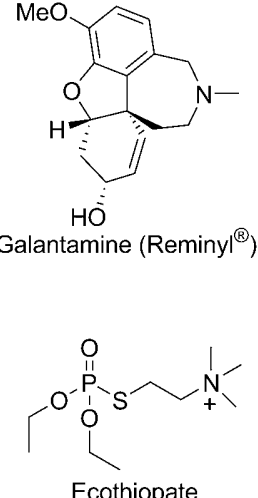

Figure 1. Bioactive acetylcholine analogues.
Other reversible AChE inhibitors, such as edrophonium, neostigmine, pyridostigmine, and ecothiopate, have chemical structures that rely on the features and motifs that compose acetylcholine (Figure 1). They all possess an alkylated ammonium unit similar to that of acetylcholine. Furthermore, all of the compounds have an oxygen atom that is separated by either two carbons from the ammonium group, as is the case in acetylcholine, or three carbons. Neostigmine, pyridostigmine, and ecothiopate all have a carbonyl or a phosphate analogue at an equivalent position to that of the acetyl group of acetylcholine. These successful examples suggest that the following motifs should be considered in the search for and design of novel acetylcholine-based bioactive compounds: 1) the compounds should have an ammonium functional group, and 2) the ammonium group should be placed in a two $\mathrm{C}-\mathrm{C}$ distance from the acyl group. A variety of acyl groups at the oxygen might improve the activity. As such, the design and synthesis of acetylcholine-based compound libraries has a great potential for the discovery of novel acetylcholine analogues that can act as AChE inhibitors and/or as specific receptor agonists.

Previously, Kim et al. ${ }^{[19]}$ briefly explored the substrate promiscuity of human choline acetyltransferase (hChAT) and showed that the enzyme requires two major aspects of the choline compound. Choline derivatives must maintain the ethanolamine core both in number of atoms and substitution pattern. Investigations of the hChAT cosubstrate (acetyl-CoA) promiscuity have not been reported.

In this study, we developed a chemoenzymatic method that provides facile and rapid access to a large number of novel acetylcholine analogues that would otherwise require several synthesis and purification steps, which would significantly increase the efforts for the preparation of libraries to be used for high-throughput screening. We used hChAT to generate novel acylcholine compounds using a variety of choline and CoA 
analogues (Scheme 1). Earlier work has set the precedent that acetylated choline analogues can behave as AChE inhibitors, for example, hemicholinium-3 (HC), which when acetylated

tion, compounds $10,11,13$, and 14 demonstrate that substituting the terminal proton of propylcholine with one or more heteroatoms also disrupts the ability of hChAT to acetylate these compounds. Interestingly, benzylcholine (15) does not become acetylated and phenylethylcholine (16) does. The ethylphenyl group resembles $\mathrm{HC}$, which is known to fit into the active site, and implies that too much rotational freedom prohibits the choline analogues from binding to the hChAT active site. These results suggest that the channel might be smaller than originally thought. We also tested a few compounds with double substitutions. Diethylcholine and dibutylcholine (not shown) demonstrated no activity with hChAT; this led us to conclude that the choline analogues require two methyl groups or a constrained cyclic structure for catalysis to take place. ${ }^{[19]}$

On the CoA side, we observed that compounds $\mathbf{2 8 - 3 0}$ and 33

forms acetylseco-HC. ${ }^{[13]}$ Using our proposed chemoenzymatic strategy with various combinations of CoA derivatives and choline analogues, we generated a library of compounds with potential AChE inhibitory activity and demonstrated the hChAT cosubstrate promiscuity.

Shown in Scheme 1 are the proposed combinations of choline (substrates) and CoA (cosubstrates) analogues. It is reported that $\mathrm{HC}$ is a substrate for hChAT. ${ }^{[19]}$ The results of the reactions with the various combinations tested are shown in Table 1. Choline analogues 5-8, 10-15, 17, and 19 did not react well with acetyl-CoA when using hChAT, and were therefore not pursued further with other $\operatorname{CoA}$ analogues. The unreactive aspect of compounds 5-8, 12, and 19 imposes a limit to the length of the choline derivative. Propylcholine (4) reacted well with acetyl-CoA, however, the addition of a methylene as in butylcholine (5) removed much of the reactivity. In addi- did not work with any of the choline analogues tested. The data show that having an extended carbonyl in the CoA derivative will also hinder the binding of the CoA. This is the first report of hChAT cosubstrate promiscuity. Other acetyltransferases have also been shown to be cosubstrate promiscuous, including aminoglycoside acetyltransferases $(\mathrm{AACs})^{[20]}$ and $\mathrm{N}$ acetyltransferases from the Gcn-5 family. ${ }^{[21]}$

From the kinetic data (Table 2), we can see that hChAT has a similar $K_{\mathrm{m}}$ for choline as previously reported. ${ }^{[19]}$ In our hands choline has a $K_{\mathrm{m}}$ of $(0.59 \pm 0.12) \mathrm{mm}$ with a catalytic turnover $\left(k_{\text {cat }}\right)$ of $(1.04 \pm 0.02) \mathrm{s}^{-1}$ and yields an overall efficiency $\left(k_{\text {cat }} / K_{\mathrm{m}}\right)$ of $1.78 \mathrm{~mm}^{-1} \mathrm{~s}^{-1}$; the previously reported $K_{\mathrm{m}}$ is $0.17 \mathrm{~mm} \cdot{ }^{[19]}$ It is important to note that the previously reported enzyme had the $\mathrm{N}$-terminal tag cleaved from the protein and we chose to leave the tag intact. Experiments were also performed to determine the kinetic parameters of acetyl-CoA, which displayed

Table 1. Compounds tested and generated by using hChAT.

\begin{tabular}{|c|c|c|c|c|c|c|c|c|c|c|}
\hline \multirow[t]{2}{*}{ Substrate } & \multicolumn{10}{|c|}{ Cosubstrate } \\
\hline & 20 & 21 & 22 & 23 & 24 & 25 & 26 & 27 & 31 & 32 \\
\hline 1 & $34^{[\mathrm{a}]}$ & $35^{[a]}$ & $36^{[\mathrm{b}]}$ & $37^{[c]}$ & $38^{[c]}$ & $39^{[c]}$ & $40^{[b]}$ & $41^{[a]}$ & $45^{[b]}$ & $46^{[a]}$ \\
\hline 2 & $47^{[a]}$ & $48^{[a]}$ & $49^{[\mathrm{a}]}$ & $50^{[b]}$ & $51^{[\mathrm{b}]}$ & $52^{[c]}$ & $53^{[\mathrm{b}]}$ & $54^{[b]}$ & $55^{[\mathrm{a}]}$ & $56^{[a]}$ \\
\hline 3 & $57^{[\mathrm{a}]}$ & $58^{[a]}$ & $59^{[\mathrm{b}]}$ & $60^{[c]}$ & $61^{[c]}$ & $62^{[c]}$ & $63^{[b]}$ & $64^{[a]}$ & $65^{[\mathrm{b}]}$ & $66^{[a]}$ \\
\hline 4 & $67^{[a]}$ & $68^{[a]}$ & $69^{[\mathrm{b}]}$ & $70^{[c]}$ & $71^{[c]}$ & $72^{[\mathrm{c}]}$ & $73^{[c]}$ & $74^{[c]}$ & $75^{[\mathrm{c}]}$ & $76^{[\mathrm{b}]}$ \\
\hline 9 & $77^{[\mathrm{a}]}$ & $78^{[\mathrm{a}]}$ & $79^{[\mathrm{a}]}$ & $80^{[b]}$ & $81^{[b]}$ & $82^{[b]}$ & $83^{[b]}$ & $84^{[a]}$ & $85^{[\mathrm{b}]}$ & $86^{[a]}$ \\
\hline 16 & $87^{[a]}$ & $88^{[\mathrm{b}]}$ & $89^{[b]}$ & $90^{[\mathrm{b}]}$ & $91^{[\mathrm{b}]}$ & $92^{[\mathrm{c}]}$ & $93^{[c]}$ & $94^{[\mathrm{cc}]}$ & $95^{[c]}$ & $96^{[c]}$ \\
\hline 18 & $97^{[a]}$ & $98^{[\mathrm{b}]}$ & $99^{[b]}$ & $100^{[\mathrm{b}]}$ & $101^{[\mathrm{c}]}$ & $102^{[\mathrm{b}]}$ & $103^{[b]}$ & $104^{[\mathrm{c}]}$ & $105^{[\mathrm{c}]}$ & $106^{[\mathrm{c}]}$ \\
\hline
\end{tabular}

[a] Indicates a good increase in the spectrophotometric assay over $30 \mathrm{~min}$. [b] Indicates a moderate increase in the spectrophotometric assay over 30 min. [c] Indicates poor or no increase in the spectrophotometric assay over $30 \mathrm{~min}$. 
Table 2. Kinetic parameters of hChAT.

\begin{tabular}{|c|c|c|c|c|}
\hline \multicolumn{5}{|c|}{ CoA analogue kinetic parameters ${ }^{[a]}$} \\
\hline Choline analogue & CoAs & $\begin{array}{l}K_{\mathrm{m}} \\
{[\mu \mathrm{M}]}\end{array}$ & $\begin{array}{l}k_{\mathrm{cat}} \\
{\left[\mathrm{s}^{-1}\right]}\end{array}$ & $\begin{array}{l}k_{\mathrm{cat}} / K_{\mathrm{m}} \\
{\left[\mu \mathrm{M}^{-1} \mathrm{~s}^{-1}\right]}\end{array}$ \\
\hline \multirow[t]{4}{*}{ choline (1) } & $\mathrm{AcCoA}$ & $20.5 \pm 0.9^{[b]}$ & $2.4 \pm 0.4$ & 0.115 \\
\hline & ProCoA & $31.7 \pm 9.3$ & $0.31 \pm 0.001$ & 0.010 \\
\hline & CrotCoA & $7.1 \pm 2.4$ & $0.104 \pm 0.012$ & 0.015 \\
\hline & MalCoA & $19.9 \pm 1.5$ & $0.122 \pm 0.014$ & 0.006 \\
\hline \multirow[t]{4}{*}{ aminocholine (2) } & $\mathrm{AcCoA}$ & $19.4 \pm 1.1$ & $1.99 \pm 0.0118$ & 0.103 \\
\hline & ProCoA & $12.7 \pm 5.2$ & $0.197 \pm 0.065$ & 0.016 \\
\hline & BenzCoA & $2.9 \pm 0.6$ & $0.177 \pm 0.008$ & 0.061 \\
\hline & CrotCoA & $8.6 \pm 1.7$ & $0.231 \pm 0.022$ & 0.027 \\
\hline ethylcholine (3) & $\mathrm{AcCoA}$ & $14.8 \pm 3.9$ & $0.219 \pm 0.013$ & 0.015 \\
\hline propylcholine (4) & $\mathrm{AcCoA}$ & $3.8 \pm 1.0$ & $0.074 \pm 0.006$ & 0.020 \\
\hline OH-ethylcholine (9) & $\mathrm{AcCOA}$ & $18.5 \pm 6.2$ & $0.760 \pm 0.180$ & 0.041 \\
\hline propargylcholine (18) & $\mathrm{AcCoA}$ & $10.1 \pm 0.9$ & $0.122 \pm 0.013$ & 0.012 \\
\hline \multicolumn{5}{|c|}{ Choline analogue kinetic parameters ${ }^{[a]}$} \\
\hline Choline analogue & CoAs $\quad K_{\mathrm{m}}$ & & $\begin{array}{l}k_{\mathrm{cat}} \\
{\left[\mathrm{s}^{-1}\right]}\end{array}$ & $\begin{array}{l}k_{\mathrm{cat}} / K_{\mathrm{m}} \\
{\left[\mathrm{mm}^{-1} \mathrm{~s}^{-1}\right]}\end{array}$ \\
\hline choline (1) & $\mathrm{AcCoA}$ & $59 \pm 0.12^{[b]}$ & $1.04 \pm 0.02$ & 1.78 \\
\hline aminocholine (2) & $\mathrm{AcCoA}$ & $34 \pm 0.03$ & $16.2 \pm 0.04$ & 47.6 \\
\hline OH-ethylcholine (9) & AcCoA & $2 \pm 0.5$ & $0.723 \pm 0.208$ & 0.60 \\
\hline
\end{tabular}

[a] Kinetic parameters were determined at $\mathrm{pH}$ 7.5. [b] Errors were calculated from at least three independent trials of kinetic experiments. by TLC (Figure 2, representative example with aminocholine (2) and acetyl-CoA).

In summary, we have presented evidence that hChAT exhibits relaxed specificity with respect to both the substrate and

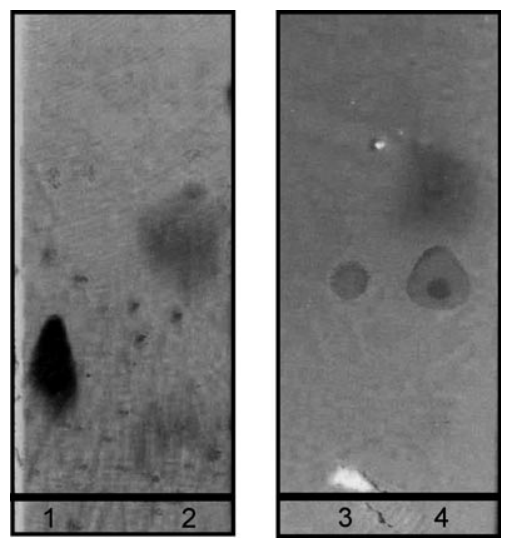

Figure 2. TLCs of aminocholine ( 2 ; lane $\left.1, R_{\mathrm{f}}=0.27\right)$, acetylaminocholine (47; lane $\left.2, R_{\mathrm{f}}=0.45\right)$, choline $\left(1 ;\right.$ lane $\left.3, R_{\mathrm{f}}=0.36\right)$, and acetylcholine (34; lane 4, $R_{\mathrm{f}}=0.64$ as a mixture with 1 ) produced by using hChAT, and visualized with Dragendorff's reagent; eluent system: 6:2:2 MeCN/MeOH/ammonium nitrate (0.5 M).

cosubstrate. We have provided experimental kinetic data for the choline derivatives, acetyl-CoA and CoA derivatives. This work delineates the limits of the hChAT enzyme as a tool for the rapid and easy production of libraries of acetylcholine analogues as potential ChE inhibitors. To further increase the diversity and scope of both substrates and cosubstrates that can be used for the rapid chemoenzymatic generation of highthroughput acetylcholine analogue libraries our observations establish the groundwork for expanding the promiscuity of the hChAT enzyme.

\section{Experimental Section}

Materials: All alkyl halides, ethanolamines, THF, choline, aminocholine, CoA derivatives, and buffer components were obtained from Sigma-Aldrich. Methanol and acetonitrile were obtained from Fisher Scientific. All compounds were used without any further purification. The hChAT was over-expressed in E. coli BL21 (DE3) cells (Invitrogen) and the pProExHTa plasmid containing the His-tagged enzyme was kindly provided by Prof. Brian Shilton (University of Western Ontario, ON, Canada). NMR spectra were recorded by using a Varian 400-MR and a $300 \mathrm{MHz}$ Bruker DPX-300. IR measurements were taken by using a Perkin-Elmer SpectrumBX FT-IR system.

Expression and purification of recombinant hChAT: The purified plasmid hChAT-pProExHTa (generously provided by Brian H. Shilton, University of Western Ontario, ON, Canada) was transformed into E. coli BL21 (DE3) competent cells for protein expression and purification. Production of the protein was performed as previously reported. ${ }^{[22]}$ Briefly, LB medium $(1 \mathrm{~L})$ supplemented with ampicillin $\left(100 \mu \mathrm{g} \mathrm{mL}^{-1}\right)$ was inoculated with $1 \mathrm{~mL}$ of an overnight culture of the transformant containing the hChAT-pProExHTa construct, and incubated with shaking $(200 \mathrm{rpm})$ at $37^{\circ} \mathrm{C}$. The cultures were 
grown to an $\mathrm{OD}_{600}$ of $\sim 0.5$, induced with isopropryl- $\beta$-thiogalactopyranoside (IPTG; $0.4 \mathrm{~mL}$ of $1 \mathrm{M}$ stock; final concentration $0.4 \mathrm{~mm}$ ) and shaken for an additional $16 \mathrm{~h}$ at $18^{\circ} \mathrm{C}$. Cells were harvested by centrifugation $\left(6000 \mathrm{rpm}, 5 \mathrm{~min}, 4^{\circ} \mathrm{C}\right.$, Beckman Coulter Aventi JE centrifuge, $\mathrm{F} 10$ rotor) and resuspended in buffer $\mathrm{A}(300 \mathrm{~mm} \mathrm{NaCl}$, $50 \mathrm{~mm} \mathrm{Na} 2 \mathrm{HPO}_{4}, \mathrm{pH} 8.0$, adjusted at room temperature, $10 \%$ glycerol). Resuspended cells were lysed (one pass at 10000-15000 psi, Avestin EmulsiFlex-C3 high-pressure homogenizer) and the cell debris was removed by centrifugation $\left(16000 \mathrm{rpm}, 60 \mathrm{~min}, 4^{\circ} \mathrm{C}\right.$, Beckman Coulter Aventi JE centrifuge, JA-17 rotor). The supernatant was then incubated with Ni-NTA agarose resin ( $3 \mathrm{~mL}$; Qiagen) at $4{ }^{\circ} \mathrm{C}$ for $2 \mathrm{~h}$ with gentle rocking. The resin was loaded onto a column and washed with buffer $A(10 \mathrm{~mL})$ containing $5 \mathrm{~mm}$ imidazole, followed with buffer $A(10 \mathrm{~mL})$ containing $20 \mathrm{~mm}$ imidazole. The desired protein was eluted from the column in a stepwise imidazole gradient $(5 \mathrm{~mL}$ fractions of $20 \mathrm{~mm}(2 \times), 40 \mathrm{~mm}(3 \times)$, $250 \mathrm{~mm}$ imidazole $(3 \times))$. Fractions containing the pure desired protein (as determined by SDS-PAGE; Figure S1) were combined and dialyzed at $4{ }^{\circ} \mathrm{C}$ against buffer $\mathrm{A}(3 \times 1 \mathrm{~L})$ for $1 \mathrm{~h}$ each. The dialyzed protein was concentrated by using Amicon Ultra PL-10, flash frozen, and stored at $-80^{\circ} \mathrm{C}$. The protein concentration was determined by using a Nanodrop spectrometer (Thermo Scientific). Protein yield was $1.5 \mathrm{mg} \mathrm{L}^{-1}$ of culture.

Determination of CoA derivatives and substrate promiscuity: A previously developed spectrophotometric assay was used to monitor the formation of 4-thiopyridone from the reaction of 4,4'-dithiodipyridine with the CoA formed from acylation of choline compounds. ${ }^{[20]}$ The assay exploits the absorbance at $324 \mathrm{~nm}$ of 4-thiopyridone, which results from reaction $(200 \mu \mathrm{L})$ of hChAT $(60 \mathrm{nM})$ with DTDP $(2 \mathrm{~mm})$, CoA derivative $(200 \mu \mathrm{M})$ and choline or choline analogue $(2 \mathrm{~mm})$ in HEPES $(50 \mathrm{~mm}, \mathrm{pH} 7.5$, adjusted at room temperature). The mixture was incubated at $37^{\circ} \mathrm{C}$ for 25 to $30 \mathrm{~min}$, and measurements were taken every $30 \mathrm{~s}$ in a high-throughput fashion by using a Spectra Max M5 microplate reader. Representative examples of "good", "moderate", and "poor" cosubstrates with various choline analogues are displayed in Figures S2-S4 in the Supporting Information.

Confirmation of reaction completion by TLC: Reactions (100 $\mu \mathrm{L})$ were carried out at $37^{\circ} \mathrm{C}$ in HEPES $(50 \mathrm{~mm}, \mathrm{pH} 7.5$, adjusted at room temperature) in the presence of acetyl-CoA $(11 \mathrm{mM})$, choline analogue $(10 \mathrm{~mm})$, and hChAT $(36 \mu \mathrm{M})$, overnight. Aliquots $(10 \mu \mathrm{L})$ of each reaction were loaded onto a TLC plate (EMD, Silica gel F254 $250 \mathrm{~mm}$ thickness). The eluent system utilized was 6:2:2 $\mathrm{MeCN} / \mathrm{MeOH} / \mathrm{ammonium}$ nitrate $(0.5 \mathrm{M})$, and visualization was achieved by using Dragendorff's reagent (solution $\mathrm{A}: 0.17 \mathrm{~g} \mathrm{BiNO}_{3}$ in $2 \mathrm{~mL} \mathrm{AcOH}, 8 \mathrm{~mL} \mathrm{H} \mathrm{H}_{2} \mathrm{O}$; solution $\mathrm{B}: 4 \mathrm{~g} \mathrm{KI}$ in $10 \mathrm{~mL} \mathrm{AcOH}, 20 \mathrm{~mL}$ $\mathrm{H}_{2} \mathrm{O} ; \mathrm{A}+\mathrm{B}$ were mixed and diluted to $100 \mathrm{~mL}$ in $\mathrm{H}_{2} \mathrm{O}$ ).

Determination of kinetic parameters: Kinetic parameters were determined by using the aforementioned assay. The kinetic parameters for the COA analogues were determined by holding the choline or choline derivatives constant $(2 \mathrm{~mm})$ and varying the CoA concentration ( 0 to $0.25 \mathrm{~mm}$ ). Parameters for choline and its analogues were determined by holding the acetyl-CoA concentration constant $(1 \mathrm{~mm})$ and varying the choline or choline analogue concentration ( 0 to $1 \mathrm{~mm}$ ). Parameters were calculated by using a Lineweaver-Burke regression of the initial rates (representative examples are shown in Figures S5-S8).
Synthesis of choline analogues; general procedure: In general 2(dimethylamino)ethanol was dissolved in THF or $\mathrm{MeOH}(10 \mathrm{~mL})$. The alkyl halide was added to this solution. The reaction was stirred at room temperature, overnight. If the reaction was carried out in THF the product was filtered and dried in vacuo. When $\mathrm{MeOH}$ was used, the $\mathrm{MeOH}$ was evaporated under reduced pressure and the compound recrystallized from $\mathrm{MeOH} / \mathrm{EtOAc}$. The product was then filtered and dried. These methods were inspired by the work of Dasgupta et al. ${ }^{[23]}$ See the Supporting Information for precise quantities, yields, and characterization of all compounds.

\section{Acknowledgements}

We gratefully acknowledge Dr. Brian $\mathrm{H}$. Shilton (University of Western Ontario, ON, Canada) for the generous gift of the hChAT-containing plasmid. Dr. Mi Hee Lim and Allana Mancino (University of Michigan) are also acknowledged for use of equipment.

Keywords: acylation - Alzheimer's disease - coenzyme A cosubstrates $\cdot$ enzyme promiscuity $\cdot$ inhibitors

[1] P. J. Whitehouse, J. Clin. Psychiatry 1998, 59 Suppl. 13, 19.

[2] D. J. Holt, S. E. Bachus, T. M. Hyde, M. Wittie, M. M. Herman, M. Vangel, C. B. Saper, J. E. Kleinman, Biol. Psychiatry 2005, 58, 408.

[3] D. Elwyn, A. Weissbach, S. S. Henry, D. B. Sprinson, J. Biol. Chem. 1955, 213, 281.

[4] E. K. Fifer in Foye's Principles of Medicinal Chemistry (Eds.: T. L. Lemke, D. A. Williams, V. F. Roche, S. W. Zito), Wolters Kluwer Health/Lippincott Williams \& Wilkins, Philadelphia, 2008, p. 361.

[5] E. Giacobini, Int. J. Geriatr. Psychiatry 2003, 18, S1.

[6] E. K. Perry, Age Ageing 1980, 9, 1.

[7] M. Pakaski, J. Kalman, Neurochem. Int. 2008, 53, 103.

[8] R. T. Bartus, R. L. Dean, 3rd, B. Beer, A. S. Lippa, Science 1982, 217, 408.

[9] A. Contestabile, E. Ciani, A. Contestabile, Neurochem. Res. 2008, 33, 318.

[10] D. D. Flynn, G. Ferrari-DiLeo, D. C. Mash, A. I. Levey, J. Neurochem. 1995, 64, 1888.

[11] C. P. Hansen, A. A. Jensen, T. Balle, K. Bitsch-Jensen, M. M. Hassan, T. Liljefors, B. Froølund, Bioorg. Med. Chem. Lett. 2009, $19,87$.

[12] C. P. Hansen, A. A. Jensen, J. K. Christensen, T. Balle, T. Liljefors, B. Frølund, J. Med. Chem. 2008, 51, 7380.

[13] B. A. Hemsworth, S. M. Shreeve, G. B. Veitch, Br. J. Pharmacol. 1984, 81, 685.

[14] N. Tsuno, Expert Rev. Neurother. 2009, 9, 591.

[15] J. Birks, J. Grimley Evans, V. lakovidou, M. Tsolaki, F. E. Holt, Cochrane Database Syst. Rev. 2009, CD001191.

[16] D. A. Smith, Am. J. Health Syst. Pharm. 2009, 66, 899.

[17] G. Pepeu, M. G. Giovannini, Curr. Alzheimer Res. 2009, 6, 86.

[18] A. Nordberg, T. Darreh-Shori, E. Peskind, H. Soininen, M. Mousavi, G. Eagle, R. Lane, Curr. Alzheimer Res. 2009, 6, 4.

[19] A. R. Kim, R. J. Rylett, B. H. Shilton, Biochemistry 2006, 45, 14621.

[20] M. L. Magalhaes, J. S. Blanchard, Biochemistry 2005, 44, 16275.

[21] M. Yu, L. P. de Carvalho, G. Sun, J. S. Blanchard, J. Am. Chem. Soc. 2006, $128,15356$.

[22] A. R. Kim, A. Doherty-Kirby, G. Lajoie, R. J. Rylett, B. H. Shilton, Protein Expression Purif. 2005, 40, 107

[23] A. Dasgupta, D. Das, P. K. Das, Biochimie 2005, 87, 1111

Received: May 18, 2009

Published online on July 27, 2009 